\title{
Prospective clinical experience with research biopsies in breast cancer patients
}

\author{
Ines Vaz-Luis • Catherine A. Zeghibe - Elizabeth S. Frank • Jessica Sohl • \\ Kimberly E. Washington · Stuart G. Silverman · Joseph M. Fonte • \\ Erica L. Mayer • Beth A. Overmoyer • Andrea L. Richardson · Ian E. Krop • \\ Eric P. Winer • Nancy U. Lin
}

Received: 27 August 2013/Accepted: 28 September 2013/Published online: 11 October 2013

(C) The Author(s) 2013. This article is published with open access at Springerlink.com

\begin{abstract}
There are ethical concerns regarding the performance of biopsies in patients for research purposes. We examined our single-institution experience regarding acceptance, safety, and success rate with research biopsies in patients with breast cancer. Among patients with data from paired samples, receptor status agreement between primary and metastatic samples was examined, either on first recurrence or after progression on one or more lines of therapy. An IRB-approved prospective study at the DanaFarber Cancer Institute collects research biopsies as additional passes at the time of a clinical biopsy (AB, additional biopsy) or as a separate procedure for banking purposes (RPOB, research purposes only biopsy). Biopsies are not linked to a specific therapeutic or correlative trial. Grade 2-5 adverse events are prospectively collected. 151 patients were included in the analytic cohort (total procedures $=161) ; 80.8 \%$ underwent $\mathrm{AB}, 17.2 \%$ underwent RPOB, and $2.0 \%$ underwent both $\mathrm{AB}$ and RPOB. Most
\end{abstract}

Ines Vaz-Luis and Catherine A. Zeghibe are co-first-authors.

I. Vaz-Luis · C. A. Zeghibe · E. S. Frank · J. Sohl ·

E. L. Mayer - B. A. Overmoyer - A. L. Richardson .

I. E. Krop · E. P. Winer · N. U. Lin ( $\square)$

Dana-Farber Cancer Institute, 450 Brookline Avenue, Boston,

MA 02215, USA

e-mail: Nancy_Lin@dfci.harvard.edu

I. Vaz-Luis

Instituto de Medicina Molecular, Lisbon, Portugal

K. E. Washington · J. M. Fonte

Faulkner Hospital, Boston, MA, USA

S. G. Silverman

Brigham and Women's Hospital, Boston, MA, USA patients were white $(88.7 \%)$ with a performance status of $0-1(94.0 \%) .96 .0 \%$ of patients underwent a biopsy in the setting of known or suspected metastatic disease. Receptor status between primary cancer and recurrent research biopsies differed in $43.2 \%$ of patients with available data $(18.8 \%$ among patients who underwent the research biopsy before any systemic treatment, $48.1 \%$ after treatment). Tissue was successfully collected in $92.3 \%$ of patients undergoing $\mathrm{AB}$ and $100 \%$ patients undergoing RPOB. Only three $(2.0 \%)$ patients had adverse events $\geq$ grade-2: one grade-2 pain; one grade- 2 pneumothorax; and one grade- 3 pain. Our experience suggests research biopsies can be performed safely with a high rate of successful tissue collection. Consistent with previous reports we found a high rate of discordance between primary and metastatic samples, which was even higher among treated patients. This supports continued efforts to study tissue samples at multiple points in a patient's disease course.

Keywords Breast cancer - Research biopsies · Patients' preferences $\cdot$ Receptor discordance

$\begin{array}{ll}\text { Abbreviations } \\ \text { AB } & \text { Additional biopsy } \\ \text { AE } & \text { Adverse event } \\ \text { ASE } & \text { Asymptotic standard error } \\ \text { CT } & \text { Computed tomography } \\ \text { DFCI } & \text { Dana-Farber Cancer Institute } \\ \text { ER } & \text { Estrogen receptor } \\ \text { FNA } & \text { Fine need aspirates } \\ \text { HER2 } & \text { Human epidermal growth factor receptor 2 } \\ \text { HR } & \text { Hormone receptor } \\ \text { IRB } & \text { Institutional Review Board } \\ \text { PR } & \text { Progesterone receptor } \\ \text { RPOB } & \text { Research purposes only biopsy }\end{array}$




\section{Introduction}

Research biopsies allow tumor tissue to be examined at several time-points in the disease continuum and thus provide important insights on biologic pathways, prognostic, or predictive biomarkers, and new therapeutic targets. However, since there are risks associated with a biopsy procedure and no direct benefit to participating patients, there is active debate concerning the ethics of this element of oncologic research [1-3].

Despite the risks, recent inquiries suggest that patients are willing to undergo biopsies for research purposes only [2, 4-6]. Tumor biopsies of patients enrolled in clinical trials have become more common, and data on safety, acceptance, and feasibility of invasive procedures in this context is emerging [2, 4, 5, 7-13]. Most studies suggest that research biopsies are a safe procedure, with a 0.8-1.4\% major complication rate. Risks do increase for intrathoracic biopsies, however, with a reported major complication rate of $2.4 \%$ [11, 12]. However, very limited data exists on the feasibility and safety of research biopsies performed outside of therapeutic trials.

In this analysis, we examined our experience regarding acceptance, safety, and success rate of research biopsies in breast cancer patients outside of a therapeutic or translational trial. We also examined the agreement rate between estrogen receptor (ER), progesterone receptor (PR), and human epidermal growth factor receptor 2 (HER2) among metastatic patients with paired samples, either on first recurrence or after progression through one or more lines of therapy.

\section{Subjects and methods}

An ongoing, Institutional Review Board (IRB)-approved, prospective study at the Dana-Farber Cancer Institute (DFCI) allows patients with breast cancer who are not enrolled in a trial to undergo biopsies with the single aim of banking tissue for future undetermined research. Initially, this was limited to patients with metastatic breast cancer, but was later amended to include breast cancer patients with early stage disease who had intact primaries. We examined our experience regarding the success rate and safety profile of research biopsies in these patients.

Patients enrolled between January 1, 2006 and December 31, 2012 belonged to one of two cohorts: Cohort 1 : patients undergoing clinically-indicated biopsies during which research biopsy specimens were obtained via additional passes; Cohort 2: patients undergoing biopsies for research purposes only. Except for skin biopsies, all procedures were performed under ultrasound or computed tomography (CT)-guidance by interventional radiologists.
The needle gauge used to collect tissue is between 16 and 20 gauge for core biopsies, or 22 gauge for fine needle aspirates (FNA). The size of the needle used is left to the clinical discretion of the radiologist. While the protocol calls for a goal of 3-6 core samples, or three FNAs, to be collected, ultimately the radiologist may suspend the procedure or not collect the full amount if he/she deems it unsafe for the patient.

Complication risks were reviewed as part of informed consent.

In the consent form, risks were labeled as common (more likely) and rare (less likely). Overall, common risks included local discomfort and minor bleeding, and rare risks included moderate or major bleeding, need for blood transfusion, hospitalization due to bleeding or other complications, infection, damage to nearby organs, allergic reaction to the numbing medicine. Specific language for breast, lymph node, skin or chest wall, bone, liver, lung, pleural fluid, or ascites fluid biopsies was incorporated in the consent.

It was also stated that taking part in this research study is not intended to have a direct impact on patient's health. The consent clarifies that the information learned from this research study has the potential to help the oncology community to learn more about changes that may occur in tumors and to understand the effects of future treatments for breast cancer.

It is specified in the consent process that no return of research results is anticipated.

Grade 2-5 adverse events (AEs), according to NCI CTCAE Version 4.0, were prospectively collected. Additionally, the electronic medical records were reviewed for completeness of $\mathrm{AE}$ reporting.

We used the following variables in this analysis: date of diagnosis and recurrence; age at time of biopsy; race; performance status [14]; Charlson co-morbidity score [15]; subtype defined by ER status, PR status, and HER2 status [tumor subtype was classified as hormone receptor (HR)+ (ER+ and/or PR+ and HER2-), HER2+ (HER2+, any HR), or triple negative (ER-/PR-/HER2-)]; context of the biopsy (early breast cancer or metastatic/recurrent disease); anti-cancer treatment before biopsy; date of biopsy, location of biopsy; type of biopsy; AEs; success rate. Successful biopsy was defined as one in which a research specimen was collected and banked. Among patients with data from paired samples, (primary and recurrent research biopsies), agreement (yes or no) between $\mathrm{ER}, \mathrm{PR}$, and HER2 status was tabulated and inter-rater agreement between ER, PR, and HER2 was calculated [simple kappa coefficients and asymptotic standard error (ASE)]. The agreement was performed among the entire cohort, as well as the patients that underwent research biopsies before and after systemic treatment. 
Fig. 1 Flow diagram of patient population. Note: Total number of biopsies performed in Cohort 1: 130 , total number of biopsies performed in Cohort 2:31. IRB institutional review board, DFCI Dana-Farber Cancer Institute

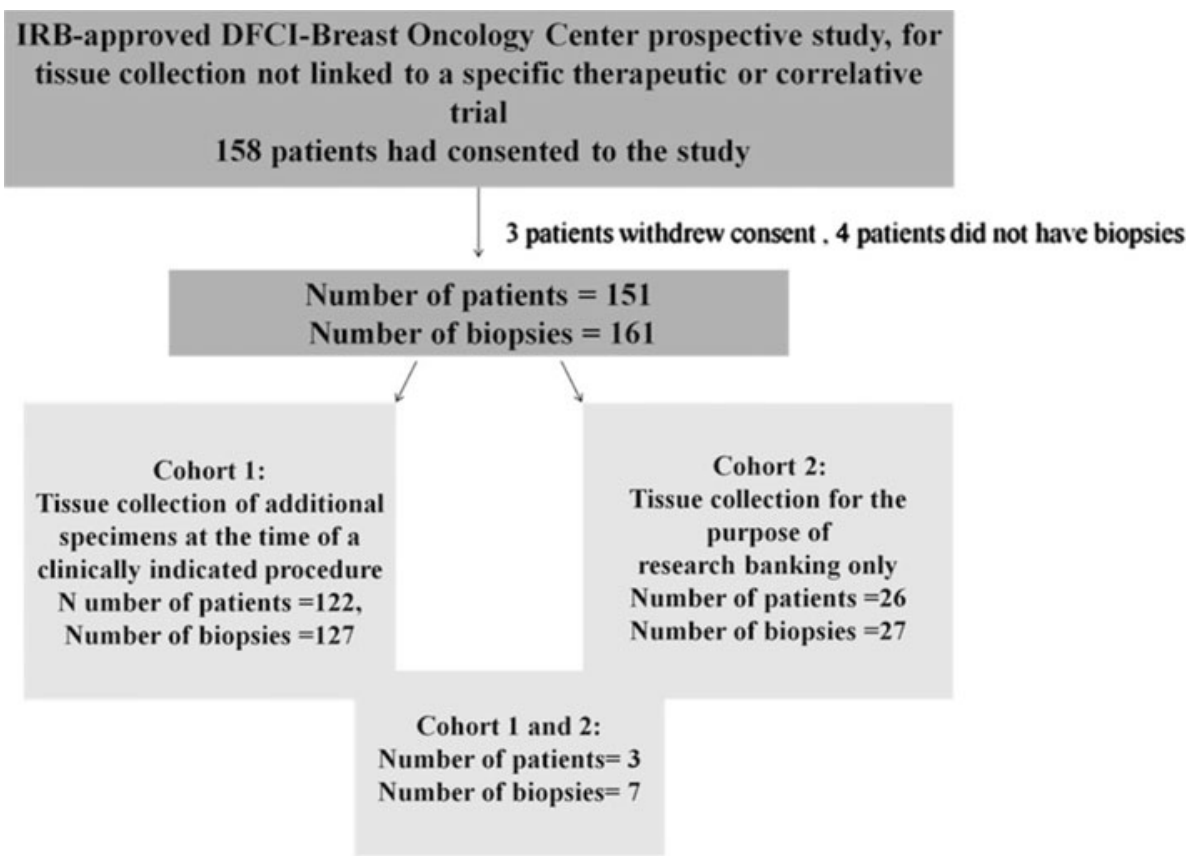

\section{Results}

158 patients consented to the study; three withdrew consent and 4 did not have biopsies. 151 patients were included in the analytic cohort, with nine patients having multiple biopsies on the protocol (total biopsies performed $=161$ ). $80.8 \%$ performed biopsies in Cohort $1,17.2 \%$ in Cohort 2, and $2.0 \%$ in both Cohort 1 and 2 (Fig. 1).

The clinical and treatment characteristics of the study population are presented in Table 1. Median age at time of research biopsy was 52.0 years (24.7-82.6). Most patients were white $(88.7 \%)$ with a performance status of $0-1$ $(94.0 \%)$ and with a co-morbidity score of $0-1(88.1 \%)$. $39.7 \%$ of biopsies were performed at time of diagnosis or first recurrence. A majority of patients $(96.0 \%)$ underwent a biopsy in the setting of known or suspected metastatic disease. Tumor subtype distribution was as following: $43.7 \%$ HR + HER $2-, 31.1 \%$ HER $2+$, and $25.2 \%$ triple negative. In $81.5 \%$ of cases patients had received prior anti-cancer therapy at the time of the research biopsy.

Research biopsies were successfully performed in 120 cases of Cohort 1 (92.3\% of the 130 performed in this cohort) and in 31 cases $(100 \%)$ of Cohort 2 . In Cohort 1 , research samples were not collected successfully in ten patients. For nine of these patients, the clinical samples had insufficient tumor tissue, leading to the forfeit of banked tissue for clinical purposes. A biopsy procedure was suspended for one patient due to severe pain (Fig. 2).

The most common sites of biopsy were liver $(37.9 \%$, $n=61)$, $\operatorname{skin}(24.2 \%, n=39)$, and breast $(18.0 \%, n=29)$. Lung was uncommon and only biopsied by fine-needle aspiration for patients in cohort $1(2.5 \%, n=4)$. Three patients in
Table 1 Baseline characteristics at time of biopsy

\begin{tabular}{|c|c|c|}
\hline & $N$ & $\%$ \\
\hline Age at biopsy (median, min-max) & $52.0(24.7-82.6)$ & \\
\hline \multicolumn{3}{|l|}{ Race } \\
\hline White & 134 & 88.7 \\
\hline Non White & 16 & 10.6 \\
\hline Unknown & 1 & 0.7 \\
\hline \multicolumn{3}{|l|}{ Performance status } \\
\hline $0-1$ & 142 & 94.0 \\
\hline 2 & 1 & 0.7 \\
\hline Unknown & 8 & 5.3 \\
\hline \multicolumn{3}{|l|}{ Comorbidity } \\
\hline $0-1$ & 133 & 88.1 \\
\hline $2+$ & 17 & 11.2 \\
\hline Unknown & 1 & 0.7 \\
\hline \multicolumn{3}{|l|}{ Cohort } \\
\hline 1 & 122 & 80.8 \\
\hline 2 & 26 & 17.2 \\
\hline 3 & 3 & 2.0 \\
\hline \multicolumn{3}{|l|}{ Context of biopsy } \\
\hline Early breast cancer & 6 & 4.0 \\
\hline Metastatic/recurrent breast cancer & 145 & 96.0 \\
\hline \multicolumn{3}{|l|}{ Breast cancer subtype } \\
\hline HR +/HER2- & 66 & 43.7 \\
\hline HER2+ & 47 & 31.1 \\
\hline HR-/HER2- & 38 & 25.2 \\
\hline \multicolumn{3}{|l|}{ Prior anti-cancer treatment } \\
\hline Yes & 123 & 81.5 \\
\hline
\end{tabular}

$\overline{H R}$ hormone receptor, $H E R 2$ human epidermal growth factor receptor 2 


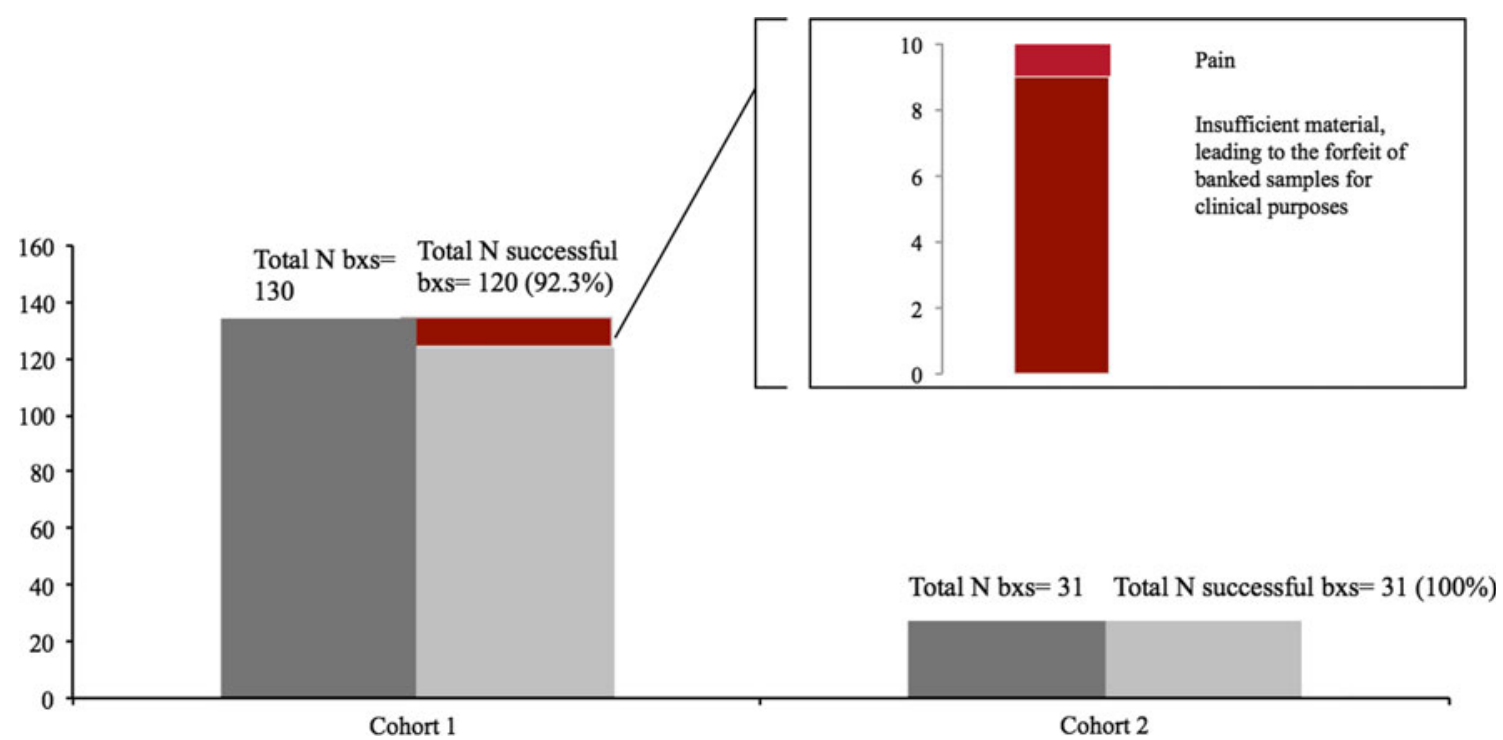

Fig. 2 Success rate of biopsies per cohort* $(N=161)$ and reasons for failure. Note: $\mathrm{N}$, number; $\mathrm{b} \times \mathrm{s}$, biopsies; * successful biopsy, biopsy in which a research specimen was collected and banked

Table 2 Summary of biopsies performed and adverse events (2006-2012)

\begin{tabular}{|c|c|c|c|c|c|c|c|c|c|c|}
\hline \multirow[t]{2}{*}{$\begin{array}{l}\text { Location of } \\
\text { biopsy }\end{array}$} & \multicolumn{3}{|c|}{$\begin{array}{l}\text { Number of biopsies } \\
\text { performed }\end{array}$} & \multirow[t]{2}{*}{$\begin{array}{l}\% \text { of biopsies } \\
\text { performed }\end{array}$} & \multicolumn{6}{|c|}{ Adverse events } \\
\hline & Total & $\begin{array}{l}\text { Cohort } \\
1\end{array}$ & $\begin{array}{l}\text { Cohort } \\
2\end{array}$ & & $\begin{array}{l}\text { Number of } \\
\text { events }\end{array}$ & $\%$ & Grade & Event & Cohort & $\begin{array}{l}\text { Context of } \\
\text { biopsy }\end{array}$ \\
\hline \multicolumn{11}{|l|}{ Chest wall } \\
\hline Breast & 29 & 17 & 12 & 18.0 & 0 & 0 & & & & \\
\hline Lymph node & 11 & 11 & 0 & 6.8 & 0 & 0 & & & & \\
\hline Skin & 39 & 24 & 15 & 24.2 & 1 & 2.6 & 3 & Pain & 1 & Progression \\
\hline Other & 1 & 1 & 0 & 0.6 & 0 & 0 & & & & \\
\hline \multicolumn{11}{|l|}{ Intra-thoracic } \\
\hline Lung & 4 & 4 & 0 & 2.5 & 1 & 25.0 & 2 & Pneumothorax & 1 & Diagnosis \\
\hline $\begin{array}{l}\text { Pleura/ } \\
\text { pericardium }\end{array}$ & 3 & 3 & 1 & 1.9 & 0 & 0 & & & & \\
\hline Mediastinum & 1 & 1 & 0 & 0.6 & 0 & 0 & & & & \\
\hline \multicolumn{11}{|l|}{ Intra-abdominal } \\
\hline Liver & 61 & 58 & 3 & 37.9 & 1 & 1.6 & 2 & Pain & 1 & Recurrence \\
\hline Soft tissue & 5 & 5 & 0 & 3.1 & 0 & 0 & & & & \\
\hline Bone & 7 & 7 & 0 & 4.3 & 0 & 0 & & & & \\
\hline
\end{tabular}

Cohort 1 experienced AEs $\geq$ grade-2: one grade-2 pain; one grade-2 pneumothorax; and one grade-3 pain. No deaths were attributable to research biopsies (Table 2).

Among patients with available data on their primary tumors, ER status changed ( $N=94$, positive to negative, or vice versa) in $18.1 \%$ of patients; PR status changed ( $N=95$, positive to negative, or vice versa) in $27.4 \%$ of patients; HER2 status changed ( $N=94$, positive to negative test) in $9.6 \%$ of patients, six out of these nine patients had at least one equivocal result. Among cases with discordance in the receptor status, in $86.5 \%$ of cases the receptors changed from a positive result to a negative one, and in $13.5 \%$ from a negative to a positive result (Table 3).

Overall, there was a $43.2 \%$ rate of any discordance between primary sample receptor status and later research biopsy tissue receptor status among all patients with available data, with a $18.8 \%$ rate of discordance among patients who underwent the research biopsy before any systemic treatment. Among patients who underwent the research biopsy after treatment there was a $48.1 \%$ rate of any discordance. 
Table 3 Agreement between ER, PR and HER2 status from primary and recurrent samples

\begin{tabular}{|c|c|c|c|c|c|c|}
\hline & ER status & $\begin{array}{l}\text { K } \\
\text { (ASE) }\end{array}$ & PR status & $\begin{array}{l}\text { K } \\
\text { (ASE) }\end{array}$ & HER2 Status & $\begin{array}{l}\text { K } \\
\text { (ASE) }\end{array}$ \\
\hline \multicolumn{7}{|c|}{ Agreement between HR and HER2 status from primary and recurrent research samples } \\
\hline Total $(N)$ & 94 & & 95 & & 94 & \\
\hline \multicolumn{7}{|c|}{ Agreement, $N(\%)$} \\
\hline Yes & $77(81.9)$ & 0.628 & $69(72.6)$ & 0.440 & $85(90.4)$ & 0.784 \\
\hline No & $17(18.1)$ & $(0.079)$ & $26(27.4)$ & $(0.086)$ & $9(9.6)$ & $(0.067)$ \\
\hline+ to - & $14(14.9)$ & & $22(23.2)$ & & $9(9.6)$ & \\
\hline- to + & $3(3.2)$ & & $4(4.2)$ & & $0(0)$ & \\
\hline \multicolumn{7}{|c|}{ Agreement before any treatment } \\
\hline Total $(N)$ & 16 & & 16 & & 16 & \\
\hline \multicolumn{7}{|c|}{ Agreement, $N(\%)$} \\
\hline Yes & $15(93.7)$ & $0.875(0.120)$ & $13(81.3)$ & $0.586(0.211)$ & $15(93.7)$ & $0.875(0.120)$ \\
\hline No & $1(6.3)$ & & $3(18.8)$ & & $1(6.3)$ & \\
\hline+ to - & $1(6.3)$ & & $2(12.5)$ & & $1(6.3)$ & \\
\hline- to + & $0(0)$ & & $1(6.3)$ & & $0(0)$ & \\
\hline \multicolumn{7}{|c|}{ Agreement after treatment } \\
\hline Total $(N)$ & 78 & & 79 & & 78 & \\
\hline \multicolumn{7}{|c|}{ Agreement, $N(\%)$} \\
\hline Yes & $62(79.5)$ & $0.569(0.092)$ & $56(70.9)$ & $0.414(0.093)$ & $70(89.7)$ & $0.750(0.081)$ \\
\hline No & $16(20.5)$ & & $23(29.1)$ & & $8(10.3)$ & \\
\hline+ to - & $13(16.7)$ & & $20(25.3)$ & & $8(10.3)$ & \\
\hline- to + & $3(3.8)$ & & $3(3.8)$ & & $0(0)$ & \\
\hline
\end{tabular}

Data was not available in a limited number of samples due to: (1) unknown information in the metastatic setting, (2) research biopsy performed at time of diagnosis. + to - : change from positive to negative marker; - to + : change from negative to positive marker

$E R$ estrogen receptor, $P R$ progesterone receptor, HER2 human epidermal growth factor 2

\section{Discussion}

This prospective study of patients with breast cancer suggests that many patients are willing to undergo research biopsies, with the single aim of banking tissue for future undetermined research, even outside the context of a therapeutic trial. Consistent with a recent survey study, which indicated a higher willingness of metastatic breast cancer patients to undergo additional passes at the time of a clinically indicated biopsy compared to a research-only biopsy, only $19.2 \%(n=29)$ of patients consented to a research-only procedure [6]. However, it is notable that 125 patients $(82.8 \%)$ consented to an additional pass at the time of a clinically indicated biopsy. Building on this approach may increase the number of patients from whom research biopsies may be obtained in a way that is acceptable to patients and providers. In addition, supporting continued efforts to study tissue samples at multiple points in a patient's disease course we found a high rate of discordance between primary and metastatic samples, which was even higher among treated patients.

Available data suggest low rates of complication related to research biopsies [8-12]. In a recent report of 745 research biopsies in 576 patients, overall and major complications rates were 5.2 and $0.8 \%$, respectively. However, the complication rate for intrathoracic biopsies was higher (17.1\% overall; $2.4 \%$ major complication) [12]. Our results are consistent with these findings, with rare (1.9\%) $\geq$ grade- 2 AEs overall, but one of eight (12.5\%) intrathoracic biopsies was complicated by grade- 2 pneumothorax. When considering which patients to enroll for research biopsies, we consider the safety of the patient first and work closely with interventional radiology to identify lesions that can be approached without undue risk. Because of the higher complication rates reported from intrathoracic sites, lung masses are targeted only in selected cases.

A prior study has suggested cancer patients consider the risk from a research biopsy of a "major complication" up to $20-25 \%$ to be acceptable. Medical oncologists and IRB personnel surveyed in the same study found a lower rate of 1-2\% risk of major complications acceptable [13]. Notably, overall, with the exception of biopsies targeting intrathoracic sites, the complication rate in our study was within the threshold deemed acceptable by medical professionals. For intrathoracic biopsies although the sample size was small, our results suggest that this may be 
associated with a higher risk, and thus should not be preferred targets, particularly for research only biopsies.

Up to this point, the quantification of the breast cancer biopsy risks is mainly driven by extrapolation from data not focused on breast cancer [8-12]. Therefore, our study provides additional information to help the medical community better quantify the risks of breast cancer research biopsies, This allows us to update the consent forms of ongoing studies and to inform future studies aiming to collect tissue from breast cancer patients .

Although not impacting directly patient care, research biopsies may provide new insights on biologic pathways, prognostic or predictive biomarkers, and help to identify new targets for therapeutics. Our analyses of discordance of receptor status between the primary and metastatic site are concordant with this concept.

Consistent with previous reports, among the overall cohort, we found a $43.2 \%$ rate of any discordance between ER, PR, and HER2 receptor status in primary and recurrent research biopsies. Furthermore, we found a lower discordance rate among patients who did not receive prior anticancer therapy versus patients who were previously treated. These data are consistent with the existence of clonal selection associated with therapy as a mechanism that contributes to discordance between paired samples. They also support the continued efforts to study tissue samples at multiple points in a patient's disease course [16]. However, it is important to stress that most of the changes occurred from a positive to a negative result, which carries fewer therapeutic implications than the reverse.

While the ethical questions surrounding research biopsies can be challenging, major insights have been gained into tumor biology as a result of studies of tumor tissue in multiple settings [17]. Many scenarios can be scientifically informative but not linked to clinically indicated biopsies; for example, biopsies at the time of progressive disease in patients who have had an extreme response to a targeted agent [18]. Putting this trial in the context of the seven Emanuel [19] ethical requirements for scientific research, a prospective cohort study with a cohort of research-only biopsies can fulfill the first two requirements of having value and scientific validity. It can also be conducted to assure fair subject selection, respect for enrolled subjects and under an independent review process, meeting another three requirements. The challenge of this particular protocol is to assure that the risks, although more than minimal, are minimized to create a favorable riskbenefit ratio and that during the informed consent process, patients are educated about the actual risks and therapeutic misconception of donating research tissue is eliminated.

The presented study has limitations. Patients were accrued at a single academic medical center, perhaps narrowing the ability to generalize results. Additionally, data on approach and decline rates to this protocol are not available, hindering understanding of both patient and physician attitudes toward collecting tissue for future research projects. The success rate of collecting tissue was used as a surrogate of evaluable tissue; however, as a majority of samples have not undergone tissue analysis, the rate of successful tissue utilization is currently undetermined. Previous studies have estimated approximately $80 \%$ of biopsy samples are usable for correlative studies [10]; therefore, it is conceivable that the majority of samples will be useful. We also did not conduct central pathology review of the tumor samples to analyze discordance in ER, PR, and HER2 receptor status between primary and metastatic samples. Finally, although we know that three patients in Cohort 1 experienced AEs $\geq$ grade-2, we are not able to assess if the complications were directly associated with the clinically indicated biopsy or with the additional pass performed for research purposes.

\section{Conclusions}

Progress in breast cancer research requires a strong partnership between researchers and patients. Maintaining the careful balance between patients' safety and understanding of risks, as well as researchers' necessity for tissue collection, is essential to ensuring advancement in the field [18]. Our data suggest that breast cancer patients are willing to undergo research biopsies, including in the metastatic setting, particularly when performed as extra passes at the time of a clinically indicated biopsy. We have observed a high rate of successful tissue collection, with an acceptable safety profile. However, additional data are needed to fully quantify the risks and to demonstrate the scientific value of these procedures. Finally, we found a high rate of discordance between primary and metastatic samples especially among treated patients. This supports continued efforts to study tissue samples at multiple points in a patient's disease course.

Acknowledgments The study was supported by the National Cancer Institute Specialized Program of Research Excellence in Breast Cancer (NIH P50 CA089393), Berry Junior Faculty Award (to NUL), the Karen Webster and David Evans Research Fund, Susan G. Komen for the Cure (to EPW), and Fundacao para a Ciencia e Tecnologia (HMSP-ICS/0004/2011, Career Development Award to IVL).

Conflict of interest BAO reported having a consultant/advisory role in Incyte Pharmaceuticals. All other authors declare that they have no competing interests.

Open Access This article is distributed under the terms of the Creative Commons Attribution Noncommercial License which permits any noncommercial use, distribution, and reproduction in any medium, provided the original author(s) and the source are credited. 


\section{References}

1. Peppercorn J, Shapira I, Collyar D, Deshields T, Lin N, Krop I, Grunwald H, Friedman P, Partridge AH, Schilsky RL, Bertagnolli MM (2010) Ethics of mandatory research biopsy for correlative end points within clinical trials in oncology. J Clin Oncol 28(15):2635-2640. doi:10.1200/JCO.2009.27.2443

2. Kodish E, Stocking C, Ratain MJ, Kohrman A, Siegler M (1992) Ethical issues in phase I oncology research: a comparison of investigators and institutional review board chairpersons. J Clin Oncol 10(11):1810-1816

3. Olson EM, Lin NU, Krop IE, Winer EP (2011) The ethical use of mandatory research biopsies. Nat Rev Clin Oncol 8(10):620-625. doi:10.1038/nrclinonc.2011.114

4. Joffe S, Cook EF, Cleary PD, Clark JW, Weeks JC (2001) Quality of informed consent in cancer clinical trials: a crosssectional survey. Lancet 358(9295):1772-1777. doi:10.1016/ S0140-6736(01)06805-2

5. Daugherty C, Ratain MJ, Grochowski E, Stocking C, Kodish E, Mick R, Siegler M (1995) Perceptions of cancer patients and their physicians involved in phase I trials. J Clin Oncol 13(5):1062-1072

6. Seah DS, Scott SM, Najita J, Openshaw T, Krag K, Frank E, Sohl J, Stadler ZK, Garrett M, Silverman SG, Peppercorn J, Winer EP, Come SE, Lin NU (2013) Attitudes of patients with metastatic breast cancer toward research biopsies. Ann Oncol. doi:10.1093/ annonc/mdt067

7. Pentz RD, Xu Z, Lonial S, Kauh JS, O'Regan RM, Waller EK, Shin DM, Fu H, Khuri F (2008) Research participants' views of nontherapeutic biopsies. ASCO Meet Abstr 26(15):13529

8. Dowlati A, Haaga J, Remick SC, Spiro TP, Gerson SL, Liu L, Berger SJ, Berger NA, Willson JK (2001) Sequential tumor biopsies in early phase clinical trials of anticancer agents for pharmacodynamic evaluation. Clin Cancer Res 7(10):2971-2976

9. Brown AP, Wendler DS, Camphausen KA, Miller FG, Citrin D (2008) Performing nondiagnostic research biopsies in irradiated tissue: a review of scientific, clinical, and ethical considerations. J Clin Oncol 26(24):3987-3994. doi:10.1200/JCO.2008.16.9896

10. Gomez-Roca CA, Lacroix L, Massard C, De Baere T, Deschamps F, Pramod R, Bahleda R, Deutsch E, Bourgier C, Angevin E,
Lazar V, Ribrag V, Koscielny S, Chami L, Lassau N, Dromain C, Robert C, Routier E, Armand JP, Soria JC (2012) Sequential research-related biopsies in phase I trials: acceptance, feasibility and safety. Ann Oncol 23(5):1301-1306. doi:10.1093/annonc/ mdr383

11. El-Osta H, Hong D, Wheler J, Fu S, Naing A, Falchook G, Hicks M, Wen S, Tsimberidou AM, Kurzrock R (2011) Outcomes of research biopsies in phase I clinical trials: the MD Anderson cancer center experience. Oncologist 16(9):1292-1298. doi:10. 1634/theoncologist.2011-0043

12. Overman MJ, Modak J, Kopetz S, Murthy R, Yao JC, Hicks ME, Abbruzzese JL, Tam AL (2013) Use of research biopsies in clinical trials: are risks and benefits adequately discussed? J Clin Oncol 31(1):17-22. doi:10.1200/JCO.2012.43.1718

13. Agulnik M, Oza AM, Pond GR, Siu LL (2006) Impact and perceptions of mandatory tumor biopsies for correlative studies in clinical trials of novel anticancer agents. J Clin Oncol 24(30):4801-4807. doi:10.1200/JCO.2005.03.4496

14. Oken MM, Creech RH, Tormey DC, Horton J, Davis TE, McFadden ET, Carbone PP (1982) Toxicity and response criteria of the Eastern cooperative oncology group. Am J Clin Oncol 5(6):649-655

15. Charlson ME, Pompei P, Ales KL, MacKenzie CR (1987) A new method of classifying prognostic comorbidity in longitudinal studies: development and validation. J Chronic Dis 40(5):373-383

16. Pusztai L, Viale G, Kelly CM, Hudis CA (2010) Estrogen and HER-2 receptor discordance between primary breast cancer and metastasis. Oncologist 15(11):1164-1168. doi:10.1634/theoncologist.20100059

17. Wagle N, Emery C, Berger MF, Davis MJ, Sawyer A, Pochanard $\mathrm{P}$, Kehoe SM, Johannessen CM, Macconaill LE, Hahn WC, Meyerson M, Garraway LA (2011) Dissecting therapeutic resistance to RAF inhibition in melanoma by tumor genomic profiling. J Clin Oncol 29(22):3085-3096. doi:10.1200/JCO.2010.33.2312

18. Peppercorn J (2013) Toward improved understanding of the ethical and clinical issues surrounding mandatory research biopsies. J Clin Oncol 31(1):1-2. doi:10.1200/JCO.2012.44.8589

19. Emanuel EJ, Wendler D, Grady C (2000) What makes clinical research ethical? J Am Med Assoc 283(20):2701-2711 